\title{
Examining Organizational Commitment and Psychological Capital in Indian Bank Employees
}

\author{
Jain, S. ${ }^{1}$, Kumar, S. \\ ${ }^{\text {I }(C e n t r e ~ f o r ~ E a r l y ~ C h i l d h o o d ~ D e v e l o p m e n t ~ \& ~ R e s e a r c h, ~ J a m i a ~ M i l l i a ~ I s l a m i a, ~ I n d i a) ~}$ \\ ${ }^{2}$ (Department of Psychology, University of Delhi, India)
}

\begin{abstract}
The objective of the present research was to understand the sector differences (public vs. private) in Indian banks on organisational commitment. The study also tries to understand the relationship between psychological capital and organisational commitment in the banking sector. The sample comprised of 147 middle level managers, above 25 years of age, working in public and private banks. The organizational commitment questionnaire and the psychological capital questionnaire were administered and descriptive and inferential statistics were used for analysis. On the basis of public and private sector, no significant differences were found on organizational commitment but the public sector employees had significantly higher continuance commitment than the private sector. It was found that there is a significant relationship between psychological capital and organizational commitment. The study has implications for designing psychological interventions to enhance organizational commitment.
\end{abstract}

Keywords: affective commitment, continuance commitment, organisational commitment, psychological capital, public v/s private

\section{INTRODUCTION}

India is one of the largest available workforces in the world. The TeamLease Indian Labor Report (2009) estimated that 300 million people will enter the labour force by 2025 , and that by then, 25 percent of the world's skilled workers will be Indians. A report by the Confederation of Indian Industries and Deloitte, a professional services firm, stated that Indian workplaces have become an interesting blend of three generations the business leaders and CEOs of baby boomer generation (45 plus), management teams and senior professionals from Gen X (23-45) and young Gen Y professionals (under 23). These statistics indicate the need to locate our understanding of organizational psychology particularly in the Indian work context.

The Indian work context per se is an interesting work setting having features of both individualistic and collectivistic work cultures. With strong joint family systems and a prevalent caste system, India has been a collectivistic and status driven society where individuals tend to put the good of the many before their own interests [1] and at the same time has high power distance where inequalities are expected and expected. However, in the post 1991 era, economic changes in India's market and the increased exposure of India's workers to western cultures and values, appears to have led to a greater emphasis on individual self-interest, personal achievement, wealth accumulation and entrepreneurship [2] If India's culture is becoming less collectivistic [3], scholars also need to consider how these changes in values may influence their attitudes and behaviours as the macroeconomic context plays a critical role in explaining the variances in employees' attitudes [4] particularly organizational commitment.

Commitment can be understood as attachment, identification, or loyalty to the entity of the commitment [5]. While organizational commitment can be understood as "the relative strength of an individual's identification with and involvement in a particular organization" [6] and the nature of the employee's attachment to their organisation [7]. Organizational commitment remainsto be an extensively deliberated phenomena in the organizational behaviourscholarship. Employee behaviours like job performance, punctuality at work, citizenship behaviour, job satisfaction, absenteeism, and turnoverare linked to OC. [8, 9, 10, 11]. Fostering employees' organizational commitment is a prime concern for contemporary organizations globally to retain talented employees in a knowledge-driven economy[12, 13] as well as in changing cultural ethosparticularly in developing countries.

The most popular conceptualization of OC is Meyer and Allen's model of organizational commitment that identifies three components, namely, affective, continuance, and normative [14, 15].Employees may develop all forms of OC with different roles and tenure, but affective commitment has consistently been found to be most cherished kind of commitment for an organization [16]. Employees' emotional attachment to, and identification with an organization can be understood as affective commitment. It truly motivates employees to 
contribute meaningfully to their organizations and has been found to be positively associated with work effort and performance [17, 18], organizational citizenship behaviour [19], and negatively linked to absenteeism, intention to leave, workplace stress, and turnover [20,21] and it is most beneficial facet of commitment to enhance organizational effectiveness [22].

Continuance commitmentis based on evaluation of perceived costs of staying v/s leaving an organization and is influenced by tenure and the position of the employee as the investment in the organization maybe too high to separate [23] and financial obligations, health benefits, and pensions may become important "side bets" [24]. Individuals possessing high level of continuance commitment also have increased levels of role conflict and role ambiguity as well as low withdrawal cognitions [19].

Normative commitment reflects employees' sense of obligation to their organization i.e. they feel they ought to stick with the organization. Normative commitment often centres on a person's own moral compass and sense of responsibility to the organization [25]. Such an obligation is the result from a person's internalized normative pressure [26].It has been found to be positively associated with both affective commitment and to various on-the- job behaviours [27, 28].

Studies have found various predictors of organizational commitment including personal characteristics, work experiences, job characteristics, role states, group/leader relations, leadership behaviour, and organizational characteristics [29, 30]. Research has shown that psychological resource capacities do have a positive impact on work-related outcomes such as work engagement and organisational commitment [31].

Like other fields in psychology, an emphasis on positive constructs and ideas of growth have taken centre stage in research in organizational behaviour. The last decade alone has witnessed an increase in the research under the umbrella term of positive organizational scholarship [32] which attempts to capture role of organizations in developing human strength, foster vitality and resilience and unlocking the residing potential in an individual. Under this scholarship, Positive organizational behaviour is of relevance and it is defined as "the study and application of positively oriented human resources strengths and psychological capacities that can be measured, developed, and effectively managed for performance improvement in today's workplace"'[33]. After a systematic analysis of the constructs in positive psychology, four capacities namely hope, efficacy, resilience, and optimism (acronym HERO) were determined to be the best fit to the concept of POB [34] and are seen as part of an interactive, synergistic resource set, rather than being in isolation and completely independent psychological constructs. These constructs together form Psychological Capital or PsyCap. PsyCap is defined as "an individual's positive psychological state of development that is characterized by: (1) having confidence (efficacy) to take on and put in the necessary effort to succeed at challenging tasks; (2) making a positive attribution (optimism) about succeeding now and in the future; (3) persevering toward goals and when necessary, redirecting paths to goals (hope) in order to succeed; and (4) when beset by problems and adversity, sustaining and bouncing back and even beyond (resilience) to attain success."[35]

The different dimensions of PsyCap have been shown to have a positive correlation with organisational commitment [36]. Empirical research has found that organisational commitment is correlated with hope, optimism, resilience and self-efficacy [31,37]. Hope as one of the dimensions of PsyCap hasbeen documented to be important in the workplace [38]. It has a positive effect on employee satisfaction, organisational commitment and work happiness[31] and it predicts job performance beyond cognitive ability and self-efficacy[39]. Hope also protects an individual's perceptions of helplessness, uncontrollability and randomness [40] and thus sustaining employees' hope is essential for employee wellbeing [41].

Self-efficacy or Efficacy from the acronym HERO has been shown to be related to the socialisation and retention of new employees [42] as well as being related to organisational commitment and turnover intentions of existing staff [43].It could have a mediating effect on occupational stress, burnout and work engagement [44].

Research linking resilience with workplace performance indicates that when employees experience negative events in the workplace, individuals with high PsyCap are more likely to adapt positively and bounce back from those events, thus preventing the escalation and development of intentions to quit. Resilience has been associated with positive emotions, especially when an individual is experiencing a taxing event [45] and is related to commitment, work engagement and work happiness [46]. It has also been linked to more effective coping mechanisms and behaviours that facilitate growth and development which may lead to higher overall commitment to the organisation, even though employees may experience their current situation and job requirements as unfavourable.

Optimism, another dimension under PsyCap, is defined by persistence and pervasiveness - two key dimensions of how people explain events [47]. People with an optimistic outlook see setbacks as challenges and opportunities that can eventually lead to success [35] and persevere in the face of obstacles [48]. In the organizational context, an optimistic employee is better able to assess external, impermanent and situational circumstances. Further optimism is correlated with employee engagement and employee performance [49, 50]. 


\subsection{The Present Study}

The Banking sector is an important component of financial sector for proper management of financial resources across the globe [51] and acts as an important pillar in the economic development of the country. In India, the banking sector is growing with a remarkable pace since independence and contribute about $65 \%$ of the GDP of the country. The experiences of employees and subsequently their performance would be greatly influenced by the type of bank one is employed with - private or public.This study seeks to unravel the relationship between the variables of Organizational Commitment and Psychological Capital in the booming Banking Sector which posits unique challenges for the employees, employers and management in the changing Indian economy and the changing ethos of the Indian customers.

In today's work environment, human capital - flexibility, innovation, and speed-to-market, effectively developing and managing employees' knowledge, experiences, skills, and expertise, has become a key success factor for sustained organizational performance [35]. Like human capital, the recognition of and investment in social capital seems vital to the success and competitive advantage of organizations both today and tomorrow. The time has now come to go beyond both these types of assets and embrace what is called as "positive psychological capital." Further, thecontemporary work place is enveloped by the fear of downsizing, loss of job security, overwhelming change in technology, and the stress of having to do more with less, there is a need to establish the type of caring, spirited workplace that will ignite employee commitment.

\subsection{Objectives}

- To examine differences between public and private sector bank employees on organizational commitment, affective commitment, normative commitment and continuance commitment.

- To study the relationship between psychological capital and organizational commitment.

- To examine whether psychological capital is a predictor of organisational commitment.

\subsection{Hypotheses}

- There is a significant difference in organisational commitment, affective commitment, normative commitment and continuance commitment of public and private sector bank employees.

- There is a significant relationship between psychological capital and organisational commitment.

- Psychological capital can significantly predict the value of organisational commitment.

\subsection{Sample}

\section{METHOD}

The total sample consists of 147 bank employees working in Delhi. Out of which 72 are working in the public sector and 75 in the private sector. A total of 158 survey instrument were distributed out of which 11 had to be rejected because of missing data. The sample descriptive of the participants is given in Table 1 .

Table 1. Sample Description

\begin{tabular}{|c|c|c|}
\hline \multirow{2}{*}{ Category } & \multicolumn{2}{|c|}{ Sample Split $(\mathbf{n = 1 4 7 )}$} \\
\hline \multirow{2}{*}{ Sector } & Public & 72 \\
\cline { 2 - 3 } & Private & 75 \\
\hline \multirow{2}{*}{ Gender } & Male & 74 \\
\cline { 2 - 3 } & Female & 73 \\
\hline \multirow{2}{*}{ Marital Status } & Unmarried & 64 \\
\cline { 2 - 3 } & Married & 83 \\
\hline
\end{tabular}

\subsection{Measures}

To measure the psychological capital, the Psychological Capital Questionnaire by Luthans et al. (2007) was used. The items in the scale are designed to measure four subscales of psychological capital identified as efficacy, hope, resilience and optimism. It is a self-report questionnaire and has 12 items. Responses are elicited on a 6-point Likert scale ranging from (1) strongly disagree to (7) strongly agree. To measure organizational commitment, the Organisational Commitment Questionnaire by Allen and Meyer (1970) was used. The questionnaire includes eighteen items, six items each for the subscales viz.-a-vis. Affective commitment, continuance commitment and normative commitment. Responses are elicited on a 7-point Likert scale ranging from (1) strongly disagree to (7) strongly agree.

\subsection{Procedure}

The objective of the study was to examine differences between public and private sector bank employees on organizational commitment, affective commitment, normative commitment and continuance commitment. This 
study also aims to study the relationship between psychological capital and organizational commitment. Further, the study attempts to examine whether psychological capital is a predictor of organisational commitment.

The total sample of the study was 147 participants working in public and private sector banks. The participants were of age 25 years and above. The measures of psychological capital and organizational commitment were measured using the Psychological Capital Questionnaire (Luthans, Avolio, and Avey, 2007) and Organizational Commitment Questionnaire (Allen and Meyer, 1970), respectively. The participants were approached and were briefly explained about the purpose of the study. Once the participants agreed to be a part of the study, their written consent was taken. The participants were put at ease and a comfort level between the researcher and the participant was established, so that the participant does not hesitate in revealing his/her true thoughts. The participants were informed about their right to withdraw from the study at any point, and were assured that any information provided by them would be kept confidential. This was followed by the administration of the questionnaires. The two questionnaires were scored according to the instructions given in their respective manuals and was then analysed using SPSS v. 21. The descriptive statistics of frequency, mean and standard deviation and inferential statistics of t-test and regression were calculated.

\section{RESULTS}

The descriptive statistics for Psychological Capital and Organizational Commitment for a sample of 147 participants is given in Table 2 .

Table 2. Descriptive Statistics for the Variables ( $\mathrm{n}=147$ )

\begin{tabular}{|l|l|l|}
\hline \multicolumn{1}{|c|}{ Variable } & Mean & S.D. \\
\hline Efficacy & 4.90 & 0.696 \\
\hline Hope & 4.49 & 0.698 \\
\hline Resilience & 4.16 & 0.884 \\
\hline Optimism & 4.95 & 1.051 \\
\hline Psychological Capital & 4.59 & 0.560 \\
\hline Affective Organization Commitment & 29.39 & 5.995 \\
\hline Continuance Organization Commitment & 26.04 & 7.001 \\
\hline Normative Organizational Commitment & 27.73 & 6.155 \\
\hline Total Organizational Commitment & 83.16 & 13.256 \\
\hline
\end{tabular}

Sector differences for Organizational Commitment and its components are given in Table 3.

Table 3. Sector Differences for Organizational Commitment using t -test $(\mathrm{n}=147)$

\begin{tabular}{|c|c|c|c|c|c|c|}
\hline \multirow{2}{*}{ Variables } & \multicolumn{2}{|c|}{ Public } & \multicolumn{2}{|c|}{ Private } & \multirow{2}{*}{$t$-value } & \multirow{2}{*}{$\boldsymbol{P}$} \\
\hline & Mean & S.D. & Mean & S.D. & & \\
\hline Organizational Commitment & 83.61 & 14.25 & 82.73 & 12.31 & 0.400 & 0.69 \\
\hline Affective OrganizationalCommitment & 29.06 & 6.47 & 29.72 & 5.53 & -0.670 & 0.50 \\
\hline Continuance OrganizationalCommitment & 27.43 & 7.44 & 24.71 & 6.31 & $2.396^{*}$ & 0.02 \\
\hline Normative OrganizationalCommitment & 27.12 & 6.79 & 28.31 & 5.46 & -1.165 & 0.25 \\
\hline
\end{tabular}

$* \mathrm{p}<0.05, * * \mathrm{p}<0.01$

The correlation between Psychological Capital, Affective Organizational Commitment, Continuance Organizational Commitment, Normative Organizational Commitment, and Organizational Commitment is given in Table 4.

Table 4. Bivariate Correlations using Pearson's r ( $n=147)$ 


\begin{tabular}{|c|c|c|c|c|c|c|c|c|c|}
\hline Variables & 冚 & 홈 & 冚 & $\frac{\text { 音 }}{\text { 莺 }}$ & 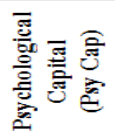 & 䓌总 & 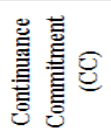 & 总总 & 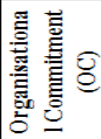 \\
\hline Efficacy & 1 & & & & & & & & \\
\hline Hope & $0.539 * *$ & 1 & & & & & & & \\
\hline Resilience & $0.415 * *$ & $0.311 * *$ & 1 & & & & & & \\
\hline Optimism & $0.235 * *$ & $0.242 * *$ & 0.107 & 1 & & & & & \\
\hline $\begin{array}{c}\text { Psychological } \\
\text { Capital }\end{array}$ & $0.772 * *$ & $0.781 * *$ & $0.686 * *$ & $0.528 * *$ & 1 & & & & \\
\hline $\begin{array}{c}\text { Affective } \\
\text { Organizational } \\
\text { Commitment }\end{array}$ & $0.241 * *$ & $0.358 * *$ & 0.052 & 0.137 & $0.287 * *$ & 1 & & & \\
\hline $\begin{array}{c}\text { Continuance } \\
\text { Organizational } \\
\text { Commitment }\end{array}$ & 0.053 & 0.123 & 0.128 & -0.039 & 0.106 & -0.19 & 1 & & \\
\hline $\begin{array}{c}\text { Normative } \\
\text { Organizational } \\
\text { Commitment }\end{array}$ & 0.092 & $0.186 *$ & 0.115 & 0.119 & $0.187 *$ & $0.324 * *$ & $0.354 * *$ & 1 & \\
\hline $\begin{array}{c}\text { Organizational } \\
\text { Commitment }\end{array}$ & $0.180 *$ & $0.314 * *$ & 0.144 & 0.097 & $0.273 * *$ & $0.593 * *$ & $0.684 * *$ & $0.798 * *$ & 1 \\
\hline
\end{tabular}

$* \mathrm{p}<0.05, * * \mathrm{p}<0.01$

The regression analysis of psychological capital as a predictor of organisational commitment is given in Table 5 .

Table 5. Predictor of Organizational Commitment using Regression Analysis

\begin{tabular}{|c|c|c|c|}
\hline \multirow{2}{*}{ Independent variable } & \multicolumn{3}{|c|}{ Dependent variable = Organizational Commitment } \\
\cline { 2 - 4 } & Beta & Simple $\mathrm{t}$ & $\mathrm{t}$ \\
\hline Psychological Capital & $0.273^{* *}$ & 0.273 \\
\hline & \multicolumn{3}{|c|}{ Multiple $\mathrm{R}=0.273 \mathrm{R}^{2}=0.074$} \\
\hline
\end{tabular}

** Significant at 0.01 Level

\section{DISCUSSION}

The purpose of the present study is to examine differences between public and private sector bank employees on organizational commitment, affective commitment, normative commitment and continuance commitment. The study also attempts to study the relationship between psychological capital and organizational commitment. Further, the study tries to examine whether psychological capital is a predictor of organisational commitment. Banking in India has been dominated by public sector banks since the 1969 when all major banks were nationalised by the Indian government. Public Sector Banks (PSBs) are banks where a majority stake (i.e. more than 50\%) is held by a government. There are a total of 27 PSBs in India [21 Nationalised banks +6 State bank group (SBI +5 associates)]. However, since liberalisation in government banking policy in the 1990s, old and new private sector banks have re-emerged. Private sector banks are those whose equity is held by private shareholders. The private sector banks are split into two groups by financial regulators in India, old and new. The old private sector banks existed prior to the nationalisation in 1969 and kept their independence because they were either too small or specialist to be included in nationalisation. The new private sector banks are those that have gained their banking license since the liberalisation in the 1990s.

\subsection{Sector Differences in Organisational Commitment}

The first hypothesis was that Organizational Commitment significantly varies with sectors. As can be seen from Table 2, no significant difference between the public and the private sector was found on total organizational commitment. Within organization commitment, no significant difference was found between the sectors on affective commitment or normative commitment either. This could be because of a similar pay scale, work environment and norms in banks from both public and private sector. This finding is parallel to the finding by Kuehn and Busaidi (2002) who found no difference in organizational commitment between nationals working in the private versus public sectors [52]. However, significant difference $(t=2.396, p<0.05)$ between the sectors was found on continuance commitment, with the public sector scoring higher $($ Mean $=27.43, \mathrm{SD}=$ 7.44 ) on it in comparison to the private sector (Mean $=24.71, \mathrm{SD}=6.31$ ). This could be because of job security, perks and allowances attached to a public sector job that make the decision of shifting to a new organization more difficult, or the possibility of not finding an equivalent position in the organization, or an equal pay scale. This finding can be supported with the help of a study done by Sood et al. (2012) that revealed significant difference in continuance commitment in private bank employees and government bank employees [53]. The government bank employees could be higher on continuance commitment due to reasons such as job security and other employment benefits in a government bank. 


\subsection{Relationship between psychological capital and organisational commitment}

The second hypothesis was that psychological capital is positively related to organisational commitment. As can be seen from Table 3 organizational commitment and psychological capital were found to be positively correlated $(\mathrm{r}=0.273)$ at a significance level of 0.01 . The significance level indicates that the obtained result was not due to chance factors. The positive correlation could be because employees with a high level of self-efficacy, hope, optimism and resilience are more likely to have cognitive and behavioural characteristics of higher self-confidence, more resiliency to adverse situations, optimism in the face of difficult situations, and hence more commitment to their organization. A study done by Ahmadi et al. (2015) is analogous to our finding, which indicated that psychological capital has positive effects on organizational commitment [54]. Within organizational commitment, affective commitment and psychological capital were found to be positively correlated $(\mathrm{r}=0.287)$ at a significance level of 0.01 . This could be because the more resilient and hopeful a person is in the face of adversity, and the more confidence he has on his efficacy, the more likely is he to feel emotionally connected to his organization and have a sense of belonging. A similar result was found by Etebarian, Tavakoli, and Abzari's (2012) in their study that revealed a positive and significant relationship between psychological capital and affective commitment [55].

The relationship between psychological capital and organisational commitment could also be attributed to the fact that psychological capital is more of a personal resource which can be implemented to enhance attitudinal outcomes such as organisational commitment. The present research has found that organisational commitment is correlated with self-efficacy $\left(r=0.180^{*}, \mathrm{p}<0.01\right)$ and hope $\left(\mathrm{r}=0.314^{* *}, \mathrm{p}<0.01\right)$. Employees who have high levels of self-efficacy and hope may be more satisfied with their job and hence, committed to their organization by the virtue of their cognitions, motivations and behaviours. Research has shown that psychological resource capacities do have a positive impact on work-related outcomes such as work engagement and organisational commitment [56]. In a study by McColl-Kennedy and Anderson (2005), there was evidence of a dependency link between optimism and commitment [57]. Sinha, Talwar, and Rajpal (2002) studied the relationship between self-efficacy and organizational commitment and found that organizational commitment is positively related with self-efficacy[37]

\subsection{Psychological capital a predictor of organisational commitment}

The third hypothesis was that psychological capital can significantly predict the value of organisational commitment.From table 5, the results of stepwise multiple regression analyses indicated that scores on Psychological Capital predicted 7.4\% of the variance in scores of Organizational Commitment $\left(\mathrm{R}^{2}=\right.$ $0.074)$, which was highly significant $F(1,145)=11.65, p<.01$. Psychological Capital $(\beta=.273, p=.01)$ demonstrated significant effect on the Organizational Commitment in bank employees. In other words, if an organization wishes to raise their employee's organizational commitment, they must work on the psychological capital of the employee i.e. provide interventions that specifically target hope, self efficacy, resilience and optimism in the employees. Research has shown that psychological resource capacities do have a positive impact on organisational commitment [31,37].Individuals with higher positive affect express more positive states and develop positive measurable actions in the personal and social relationship in comparison with individuals with lower positive affect [58].

The finding psychological capital predicts organizational commitment is highly pertinent in changing ethos of Indian organizations with employees exhibiting movement away from the collectivistic mode of operating as great Indian work families to greater emphasis on individual self-interest, personal achievement, wealth accumulation and entrepreneurship [2, 4]. As studies have demonstrated that fully committed employees lead to organizational success and thriving in today's dynamic organizational contexts [59], it is relevant to reexamine organizational commitment in the light of the psychological capital and not only human and social capital.

\section{CONCLUSION}

On the basis of public and private sector, no significant differences were found on organisational commitment. However, the public sector was found to have higher continuance commitment than the private sector. It was also seen that Psychological Capital is positively related and predicted Organizational Commitment. The findings of the study have significant implications for the management of commitment and development of psychological capital among bank employees in India. Only recruiting good employees is not enough. It is equally important that their level of commitment is built and enhanced with right kinds of policies and more emphasis is placed on developing the strengths of the employees and assigning them work based on their capability. As the banking sector involves hands-on dealing with customers, hopeful, efficacious, resilient, optimistic employees will be more likely make better relationships with the customers, improve brand recall and be committed to organizational goals. 
The sample of the present study was restricted to middle level managers working in banks of Delhi. Therefore, we cannot say that the sample was representative of public and private sector banks. A further limitation of this study is the use of self-reported questionnaires. Self-report data can give rise to socially desirable responses which could affect the reliability and validity of the data. It is recommended that future studies make use of a longitudinal design to determine the causal relationships between the variables of the study. Future studies can overcome the limitations of the generalisation of the findings by using a larger sample size across different contexts. The sample should include employees belonging to different organizations and working at different levels of employee hierarchy in order to understand sector differences in psychological capital and organizational commitment in a better and more comprehensive fashion.

\section{References}

[1] Hofstede G; Hofstede G.J. and Minkov M., Cultures and Organizations: Software of the Mind, Revised and Expanded 3rd Edition. McGraw-Hill. 2010

[2] Goswami, A., Dalmia, N. and Pradhan, M. "Entrepreneurship in India", Report for the National Knowledge Commission, Government of India. 2008

[3] Sinha, D., and Tripathi, R.C., Individualism in a collectivist culture: A case of coexistence of opposites', in Kim, U and others eds., Individualism and Collectivism: Theory, Method, and Applications. Thousand Oaks, Calif.: Sage. 1994

[4] Fischer, R. and Mansell, A. Commitment across cultures: A meta-analytical review approach, Journal of International Business Studies,40: 2009.1339-1358.

[5] Morrow, P.C., The Theory and Measurement of Work Commitment JAI Press, Greenwich, CT. 1993

[6] Mowday, R.T., Porter, L.W., \& Steers, R.M. Employee-organisation linkages: the psychology of commitment, absenteeism, and turnover. New York: Academic Press. 1982

[7] Shahnawaz, M.G., \& Jafri, H. Psychological capital as predictors of organizational commitment and organizational citizenship behaviour. Journal of the Indian Academy of Applied Psychology, 35, 20097884.

[8] Bentein, K., Robert, V., Christian, V. and Florence, S., The role of change in the relationship between commitment and turnover: a latent growth modeling approach, Journal of Applied Psychology, Vol. 90 No. 3, 2005pp. 468-482.

[9] Bogler, R., Satisfaction of Jewish and Arab teachers in Israel, The Journal of Social Psychology, Vol. 145 No. 1, 2005, pp. 19-33.

[10] Cooper-Hakim, A. and Viswesvaran, C., The construct of work commitment: testing an integrative framework, Psychological Bulletin, Vol. 131 No. 2, 2005, pp. 241-259.

[11] Dishon-Berkovits, M. and Koslowsky, M., Determinants of employee punctuality, The Journal of Social Psychology, Vol. 142 No. 6, 2002, pp. 723-739.

[12] Neininger, A., Lehmann-Willenbrock, N., Kauffeld, S. and Henschel, A. (2010), Effects of team and organizational commitment - a longitudinal study, Journal of Vocational Behaviour, Vol. 76 No. 3, pp. 567-579.

[13] Reiche, B.S. The configuration of employee retention practices in multinational corporations' foreign subsidiaries, International Business Review, Vol. 17 No. 6,2008, pp. 676-687.

[14] Meyer, J.P. and Allen, N.J. "A three-component conceptualization of organizational commitment", Human Resource Management Review, Vol. 1 No. 1,1991, pp. 61-89.

[15] Meyer, J.P. and Allen, N.J., Commitment in the Workplace: Theory, Research, and Application Sage, Thousand Oaks, CA. 1997

[16] Iverson, R.D. and Buttigieg, D.M., "Affective, normative and continuance commitment: can the 'right kind' of commitment be managed?’Journal of Management Studies, Vol. 36 No. 3, 1999, pp. 307-333.

[17] Luchak, A.A. and Gellatly, I.R. (), "A Comparison of linear and nonlinear relations between organizational commitment and work outcomes”, Journal of Applied Psychology, Vol. 92 No. 3, 2007, pp. 786-793.

[18] Vandenberghe, C., Bentein, K. and Stinglhamber, F. Affective commitment to the organization, supervisor, and work group: antecedents and outcomes, Journal of Vocational Behaviour, Vol. 64 No. 1,2004, pp. 47-71.

[19] Meyer, J.P., Stanley, D.J., Herscovitch, L. and Topolnytsky, L., “Affective, continuance, and normative commitment to the organization: a meta-analysis of antecedents, correlates, and consequences", Journal of Vocational Behaviour, Vol. 61 No. 1, 2002, pp. 20-52.

[20] Alexandrov, A., Babakus, E. and Yavas, U., The effects of perceived management concern for frontline employees and customers on turnover intentions: moderating role of employment status", Journal of Service Research, Vol. 9 No. 4, 2007, pp. 356-371. 
[21] Nasr, L., The relationship between the three components model of commitment, workplace stress and career path application to employees in medium size organization in Lebanon, Proceedings from Academy of Organizational Culture, Communications and Conflict: Allied Academies International Conference, Vol. 15 No. 2, 2010, pp. 13-27.

[22] Tornikoski, C., Fostering expatriate affective commitment: a total reward perspective, Cross Cultural Management: An International Journal, Vol. 18 No. 2, 2011, pp. 214-235.

[23] Kwantes, C.T., Culture, job satisfaction and organizational commitment in India and the Unites States, Journal of Indian Business Research, Vol. 1 No. 4, 2009, pp. 196-212.

[24] Becker, H.S., Notes on the concept of commitment, American Journal of Sociology, Vol. 66, No. 1,1960, pp. 32-42.

[25] Marsh, R. M., \& Mannari, H. Organizational commitment and turnover: A prediction study. Administrative Science Quarterly, 22(1), 1977, 57-75.

[26] Wiener, Y. Commitment in organizations: A normative view. Academy of Management Review, 7(3), 1982, 418-428.

[27] Jaros, S.J., “An assessment of Meyer and Allen's (1991) three component model of organizational commitment and turnover intentions", Journal of Vocational Behaviour, Vol. 51 No. 3, 1997, pp. 319337.

[28] Somers, M.J. Organizational commitment, turnover and absenteeism: an examination of direct and indirect effects, Journal of Organizational Behaviour, Vol. 16 No. 1, 1995, pp. 49-58

[29] Joo, B.-K., Juan, Y.H. and Jeung, C.W. The effects of core self-evaluations and transformational leadership on organizational commitment, Leadership \& Organization Development Journal, Vol. 33 No. 6, 2013, pp. 564-582.

[30] Mathieu, J. E. and Zajac, D. M., A review and meta-analysis of the antecedents, correlates and consequences of organisational commitment", Psychological Bulletin, Vol. 108,1990, pp. 171-194

[31] Youssef, C.M., \& Luthans, F. Positive organizational behavior in the workplace: the impact of hope, optimism, and resilience. Journal of Management, 33(5),2007, 774-800.

[32] Cameron KS, Caza A. Contributions to the discipline of positive organizational scholarship. Am. Behav. Sci. 47: 2004 731-39

[33] Luthans F.Positive organizational behavior: developing and managing psychological strengths. Acad. Manag. Exec. 16(1): 2002, 57-72

[34] Luthans F, Youssef CM. Human, social, and now positive psychological capital management: Investing in people for competitive advantage. Organ. Dyn. 33: 2004, 143-60

[35] Luthans F, Youssef-Morgan CM, Avolio B. Psychological Capital and Beyond. New York: Oxford Univ. Press 2015

[36] Luthans, F., Norman, S.M., Avolio, B.J., \& Avey, J.B. The mediating role of psychological capital in the supportive organizational climate-employee performance relationship. Journal of Organizational Behavior, 29(2),2008, 219-238.

[37] Sinha, S. P. Talwar, T., \& Rajpal, R. (2002). Correlational study of organizational commitment, selfefficacy and psychological barriers to technological change. Psychologia, 45(3), 176-183.

[38] Duggleby, W., Cooper, D., \& Penz, K. Hope, self-efficacy, spiritual well-being and job satisfaction. Journal of Advanced Nursing, 65(11), 2009, 2376-2385.

[39] Peterson, S.J., Walumbwa, F.O., Byron, K., \& Myrowitz, J. CEO positive psychological traits, transformational leadership, and firm performance in high-technology start-up and established firms. Journal of Management, 35(2), 2009, 348-368.

[40] Snyder, C.R. Hope theory: rainbows in the mind. Psychological Inquiry, 13(4), 2002, 249-275.

[41] Weick, K.E., \& Quinn, R.E. Organizational change and development. Annual Review of Psychology, 50, 1999, 361-386.

[42] Bauer, T.N., Bodner, T., Erdogan, B., Truxillo, D.M., \& Tucker, J.S. Newcomer adjustment during organizational socialization: A meta-analytic review of antecedents, outcomes, and methods. Journal of Applied Psychology, 92(3), 2007, 707-721

[43] Harris, G.E., \& Cameron, J.E. Multiple dimensions of organizational identification and commitment as predictors of turnover intentions and psychological well-being. Canadian Journal of Behavioural Science, 37(3), 2005, 159-169.

[44] Rothmann, S. Burnout and engagement: a South African perspective. SA Journal of Industrial Psychology/SA Tydskrif vir Bedryfsielkunde, 29(4), 2003, 16-25.

[45] Philippe, F.L., Lecours, S., \& Beaulieu-Pelletier, G. Resilience and positive emotions: Examining the role of emotional memories. Journal of Personality, 77(1), 2008, 139-175.

[46] Luthans, F., Avolio, B.J., Avey, J.B., \& Norman, S.M. Positive psychological capital: measurement and relationship with performance and satisfaction. Personnel Psychology, 60(3), 2007, 541-572. 
[47] Carver, C., \& Scheier, M. Optimism. In C.R. Snyder \& S. Lopez (Eds.), Handbook of positive psychology (pp. 231-243). New York: Oxford University Press. 2002

[48] Stajkovic, A.D., \& Luthans, F. Social cognitive theory and self-efficacy: Going beyond traditional motivational and behavioural approaches. Organizational Dynamics, 26(4), 1998, 62-74.

[49] Arakawa, D., \& Greenberg, M. Optimistic managers and their influence on productivity and employee engagement in a technology organisation: implications for coaching psychologists. International Coaching Psychology Review, 2(1), 200778-89.

[50] Medlin, B., \& Faulk, L. The relationship between optimism and engagement: the impact on student performance. Research in Higher Education Journal, 13, 20119 pages.

[51] Ahmad A, Malik M I, HumayounA.A. Banking Developments in Pakistan: A Journey from Conventional to Islamic Banking, European Journal of Social Sciences, Vol.17, No. 1. 2010

[52] Kuehn, K. W., \& Al-Busaidi, Y. A comparison of organizational commitment between national and expatriate employees in public and private sector organizations. Journal of International Business Research, 1(1),2002, 21-34.

[53] Sood, S., Bakhshi, A., \& Sharma, S. Differences in organizational commitment in private and public sector bank employees. International Journal of Research in Commerce and Management, 3(12),20125052.

[54] Ahmadi, A. A., Shahbazi, M., \& Hashemian, N. Relationship of Psychological Capital and Organization Commitment of Employees in Payame Noor University. Internal Journal of Revie of Life Sciences, 5(1), 2015.

[55] Etebarian, A., Tavakoli, S., \& Abzari, M. The relationship between psychological capital and organizational commitment. African Journal of Business Management, 6(14),2012, 5057-5060.

[56] Youssef, C.M., \& Luthans, F. Positive organizational behaviour in the workplace: the impact of hope, optimism, and resilience. Journal of Management, 33(5), 2007, 774-800.

[57] McColl-Kennedy, J.R. \& Anderson, R.D. Subordinate-manager gender combination and perceived leadership style influence on emotions, self-esteem and organizational commitment. Journal of Business Research, 58(2), 2005, 115-125.

[58] Fasihizadeh, N., Oreyzi, H. and Nouri, A. Investigation of Positive Affect and Emotional Intelligence Effect on Job satisfaction among oil Refinery Personnel of Isfahan. Institute of Interdisciplinary Business Research, 4 (2),2012

[59] Lumley, E. J., Coetzee, M., Tladinyane, R., \& Ferreira, N. Exploring the Job Satisfaction and Organisational Commitment of Employees in the Information Technology Environment. Southern African Business Review, 15, 2011, 100-118. 